\title{
Predictability of the Consistency of Porridges Using Mixtures of Different Flours
}

\author{
Irene S. T. de Carvalho ${ }^{1,2 *}$, Yvonne Granfeldt ${ }^{2}$, Ann-Charlotte Eliasson ${ }^{2}$, Petr Dejmek ${ }^{2}$ \\ ${ }^{1}$ Department of Chemical Engineering, Eduardo Mondlane University, Maputo, Mozambique; ${ }^{2}$ Department of Food Technology, \\ Engineering and Nutrition, Lund University, Lund, Sweden. \\ Email: *Irene. Carvalho@food.lth.se
}

Received June $6^{\text {th }}, 2013$; revised July $6^{\text {th }}, 2013$; accepted July $13^{\text {th }}, 2013$

Copyright (C) 2013 Irene S. T. de Carvalho et al. This is an open access article distributed under the Creative Commons Attribution License, which permits unrestricted use, distribution, and reproduction in any medium, provided the original work is properly cited.

\begin{abstract}
The purpose of this study was to investigate the predictability of the consistency of blended porridges based on the volume fractions of separate porridges made from orange-fleshed sweet potato, cowpea, dehulled soybean, dehulled sorghum and maize flour (dehulled, commercial and germinated). Accurate predictions could be made for 13 of the 21 blends investigated. The consistency of porridge consisting of mixtures of cowpea with orange-fleshed sweet potato, and cowpea with dehulled soybean was lower than expected, and was attributed to the different size distributions of the swollen flour particles. Blends containing germinated maize showed significantly lower consistency than expected in both porridges with starchy continuous phase and porridges with proteinaceous continuous phase. It was thus concluded that both amylolytic and proteolytic activity are of importance in the ameliorating effects of germinated maize.
\end{abstract}

Keywords: Back-Extrusion; Consistency; Flour; Mixtures; Porridge

\section{Introduction}

Supplementary foods for malnourished children must contain several ingredients in order to provide a nutritionally balanced meal. One of the problems of formulating porridge lies in providing sufficient energy density in a porridge of acceptable consistency. In heated starch dispersions the viscosity is governed by the swollen volume of the starch granules [1]. It can thus be assumed that the swollen volume of flour particles dispersed in water at a certain temperature would be correlated with the amount of flour necessary to achieve a specific porridge viscosity. In our previous study [2] porridge was made from individual flours, and a conservative estimate of the maximum flour concentration providing porridge of acceptable consistency was obtained, based on measurements of the swelling volume. For a given flour, $i$, it is necessary to use the concentration $C_{i, \text { acceptable }}$ to achieve a volume fraction leading to an acceptable porridge consistency.

Blending flours appears promising to improve the nutritional quality and energy density of porridge, the effects of blending on the structure and consistency of a food product remain to be investigated.

For blends, can be assumed to a first approximation

\footnotetext{
"Corresponding author.
}

that the volume fraction contributions from different flours are additive, for example, if $14 \%$ orange-fleshed sweet potato flour or $26 \%$ dehulled soybean flour, separately, both give an acceptable consistency, then a blend of $7 \%$ orange-fleshed sweet potato and $13 \%$ dehulled soybean should give the same consistency. This can be formulated as a criterion when choosing the concentrations of flours in a blend required to achieve an acceptable consistency, according to the equation:

$$
\sum\left(C_{i} / C_{i, \text { acceptable. }}\right)=1 \text {; }
$$

To check the validity of this simple non-interacting model, were tested all possible binary flour combinations at $C_{i} / C_{i, \text { acceptable. }}=0.5$.

While blending flours appears promising to improve the nutritional quality and energy density of porridge, the effects of blending on the structure and consistency of a food product remain to be investigated. The purpose of this study was, therefore, to measure and predict the consistency of cooked children's porridges prepared from two-flour blends.

\section{Materials and Methods}

The raw materials studied were orange-fleshed sweet potato (Ipomoea batatas), cowpea (Vigna unguiculata), 
soybean (Glycine max), sorghum (Sorghum bicolor) and maize (Zea mays), that were chosen because they are widely grown in developing countries and partly because they are among the cheapest sources of carbohydrate, protein and fat. These raw materials were purchased in local markets in Mozambique and Tanzania and prepared according to common practice in rural areas in Africa.

Flours were prepared from the raw materials as described in our previous study [2]. Orange-fleshed sweet potato flour (OFSP) was preparing according to Kidmose et al. [3] and dried according to Bengtsson et al. [4]. The cowpea was cleaned by hand to remove stones, chaff and damaged seeds and grains, steeped in water for $10 \mathrm{~min}$, dried outdoors for 24 hours, and then ground to make cowpea flour (CP). The soybeans were boiled according to Dakwa et al. [5], dehulled using a manually operated machine (Mwakimomi, made in Morogoro, Tanzania), and then dried outdoors and ground to give dehulled soybean (DS) flour. Dehulled sorghum (DSo) flour was produced using a modification of a traditional method described by Bolade and Buraimoh [6]. The cleaned sorghum was first tempered with $4 \%(\mathrm{v} / \mathrm{w})$ water followed by decortication using a traditional dehulling machine. The grains were dried outdoors for 24 hours and ground as described above.

One fraction of the cleaned maize grains was dehulled using the rural industries machine (Morogoro, Tanzania), dried outdoors and ground to give dehulled maize (DM) flour. The other fraction was used to make germinated maize (GM) flour.

Commercial products (maize (CM) flour, Fioretto, Favero Antonio S.r.l, Padua, Italy), ready-to-use whole oat grain porridge mix (Semper AB, Espoo, Finland) and a whole oat and wheat grain porridge mix (Nestlé Sverige $\mathrm{AB}$, Helsingborg, Sweden)) for children were purchased in Sweden.

\subsection{Porridge Preparation}

In the present study, porridges were made from blends of two of the following flours: OFSP, CP, DS, DSo, DM, GM and CM using the same heating and testing procedures as previously, [2]. Forty $\mathrm{ml}$ of boiling water was added to different amounts of each flour in a $50 \mathrm{ml}$ beaker and stirred with a glass stick. The samples were kept in a boiling-water bath for $8 \mathrm{~min}$, with gentle but constant stirring. The porridge was then cooled to a temperature of $\sim 43^{\circ} \mathrm{C}$ (simulating feeding temperature), prior to analysis in a texture analyser. All samples were prepared and measured in duplicate.

The ready-to-use porridges were prepared according to each manufacturer's instructions. The results from the two products were used to define a reference interval for the acceptable level of consistency. All samples were prepared and measured in duplicate.

\subsection{Consistency Measurements}

The consistency of porridges was measured according to our previous study [2]. A Stable Micro Systems Texture Analyser (TA.XT2i, Stable Micro Systems, Godalming, UK) was used to analyse the consistency of the blends porridge samples, using the back-extrusion method. Samples were measured in the beaker in which they were cooked, and cooled to feeding temperature. All measurements were performed in duplicate on separately prepared samples.

\subsection{Particle Size}

The particle sizes were determined using a light microscope (Olympus, model BX50F4, Olympus Optical Co., Ltd., Tokyo, Japan) connected to a colour video camera (model DFK41AF02, The Imaging Source Europe GmbH, Bremen, Germany). Samples of each diluted porridge were placed on slides and viewed at $2 \times$ magnification. The particle sizes of each diluted porridge were also determined using a Mastersizer (Mastersizer 2000, Malvern Instruments Ltd., Enigma Business Park, Malvern, and Worcestershire WR14 1XZ, UK) with a pump speed of $2500 \mathrm{rpm}$, and compared with those obtained using light microscopy.

\subsection{Continuous Phase of Porridges}

To analyse the character of the continuous phase of the porridges, samples of porridge made from individual flours, prepared according to our previous study [2], were placed on slides and stained with one drop of Lugol's solution, a standard stain for starch. The sample was viewed at $5 \times$ magnification using the microscope described above.

\subsection{Amylolytic Activity of Flours}

Forty $\mathrm{ml}$ distilled water was added to $2.0 \mathrm{~g}$ potato starch and stirred with a glass rod. The samples were heated in a boiling-water bath $\left(100^{\circ} \mathrm{C}\right)$ for $8 \mathrm{~min}$, with gentle, constant stirring. The suspension of gelatinised potato starch was then cooled to a temperature of $\sim 43^{\circ} \mathrm{C}$ and appropriate amount of tested flour was added to assess amylolytic activity. The viscosity of samples were measured using a Bohlin Rotavisco model 88 BV (Bohlin Reologi AB, Ideon Science Park, Lund, Sweden) at a shear rate of 160 rpm, every 2 min for $20 \mathrm{~min}$. All samples were prepared and measured in duplicate.

\subsection{Swelling Method}

Gravity sedimentation method [2] was used to measure the swelling of individual flours or blends. All samples were prepared and measured in duplicate. 


\section{Results and Discussion}

Ready-to-use porridges were used to define a reference of acceptable level of maximum consistency. When prepared according to the manufacturer's instructions, these porridges showed back-extrusion forces in the range of 0.29 to $0.37 \mathrm{~N}$ at the consumption temperature [2].

The concentrations of the flours in the two-flour blends were chosen according to Equation (1), based on the results of the individual porridges consistency reported in our previous study [2]. The ration of each flour and total amount of mixed flour used to give $100 \mathrm{~g}$ of each porridge is given in Table 1. Given the simplicity of the approach, and the steep dependence of consistency on concentration, the predictions were fairly accurate, as seen in Figure 1 where the consistency of porridges made from two-flour blends is shown. The ration of each flour contributes to half of the consistency of the porridge. For the blends containing OFSP, DS, DSo, DM and CM flours respectively, the values obtained using the additive approach agreed with the measured blend consistencies; being in the range of acceptable consistency defined by the ready-to-use porridges. However this was not the case for some of CP blends and all GM blends.

It is well known that hydrated proteins and carbohydrates often phase separate [7] and the properties of the suspension are mainly determined by the properties of the continuous phase. The results of simple Lugol staining of samples of the porridges made with one flour are shown in Figure 2. As expected, the continuous phase is related to the dominant compositional component of the flour, with the starchy OFSP, DSo, DM and CM flours staining predominantly blue, and the high-protein flours, CP and DS, and low starch flour GM showing little staining apart from a contour leached amylose.

All blends with GM flour had a lower consistency than that predicted $(0.29-0.37 \mathrm{~N})$ by the additive model. This low consistency is in agreement with results from other studies [8-12], all of which studied GM in an attempt to find an effective method of reducing the viscosity of porridges for infants and small children. According to Mosha and Svanberg [9], the reduction in viscosity could be attributed to the amylolytic activity of the germinated flour. In this study, the protein-continuous porridges phase also showed lower viscosity than predicted. Even if the dispersed starchy phase of the protein-continuous porridges phase had been degraded by the maize amylases, it is unlikely that the viscosity of the blend would have been significantly reduced, as the continuous phase determines the viscosity of the dispersion. Therefore, may be assumed that proteases, which are known to be present in germinated maize [13], contribute significantly to the decreased viscosity of the blends of proteinaceous flours containing GM flour. The viscosity-reducing effect of GM on CP and DS flour was also observed by Obatolu and Cole [14].

Some porridge blends containing CP flour (CP-OFSP and CP-DS) showed lower viscosity that expected, see Figure 1. The amylolytic activity of CP flour by adding $\mathrm{CP}$ flour to a suspension of gelatinised potato starch was investigated. The amylolytic activity was found to be weak, about 100 times lower than that of GM flour (Figure 3). It can be seen that $0.2 \mathrm{~g}$ of $\mathrm{CP}$ gave approxi-

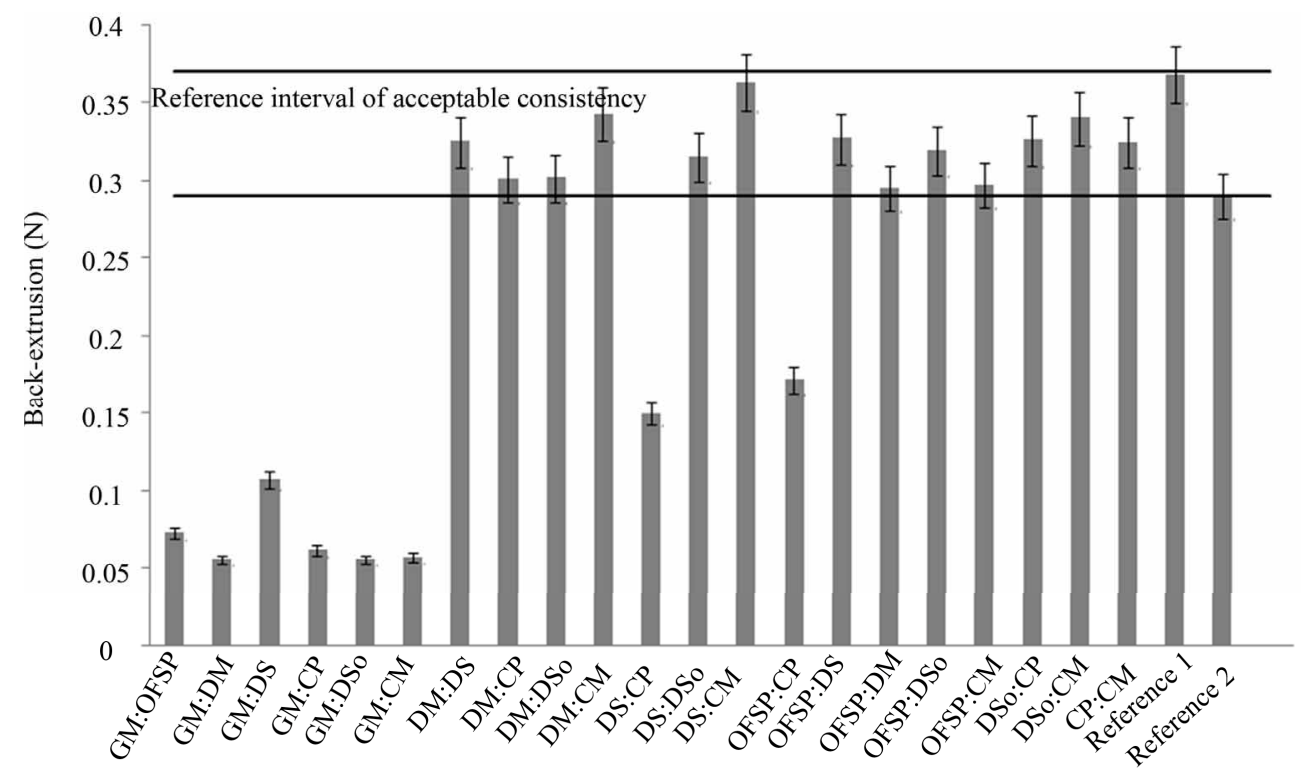

Figure 1. Consistency of porridges made from blended flours, measured by back-extrusion method: orange-fleshed sweet potato (OFSP); cowpea (CP); dehulled soybean (DS); dehulled sorghum (DSo); dehulled maize (DM); CM, commercial maize (CM); and germinated maize (GM). 

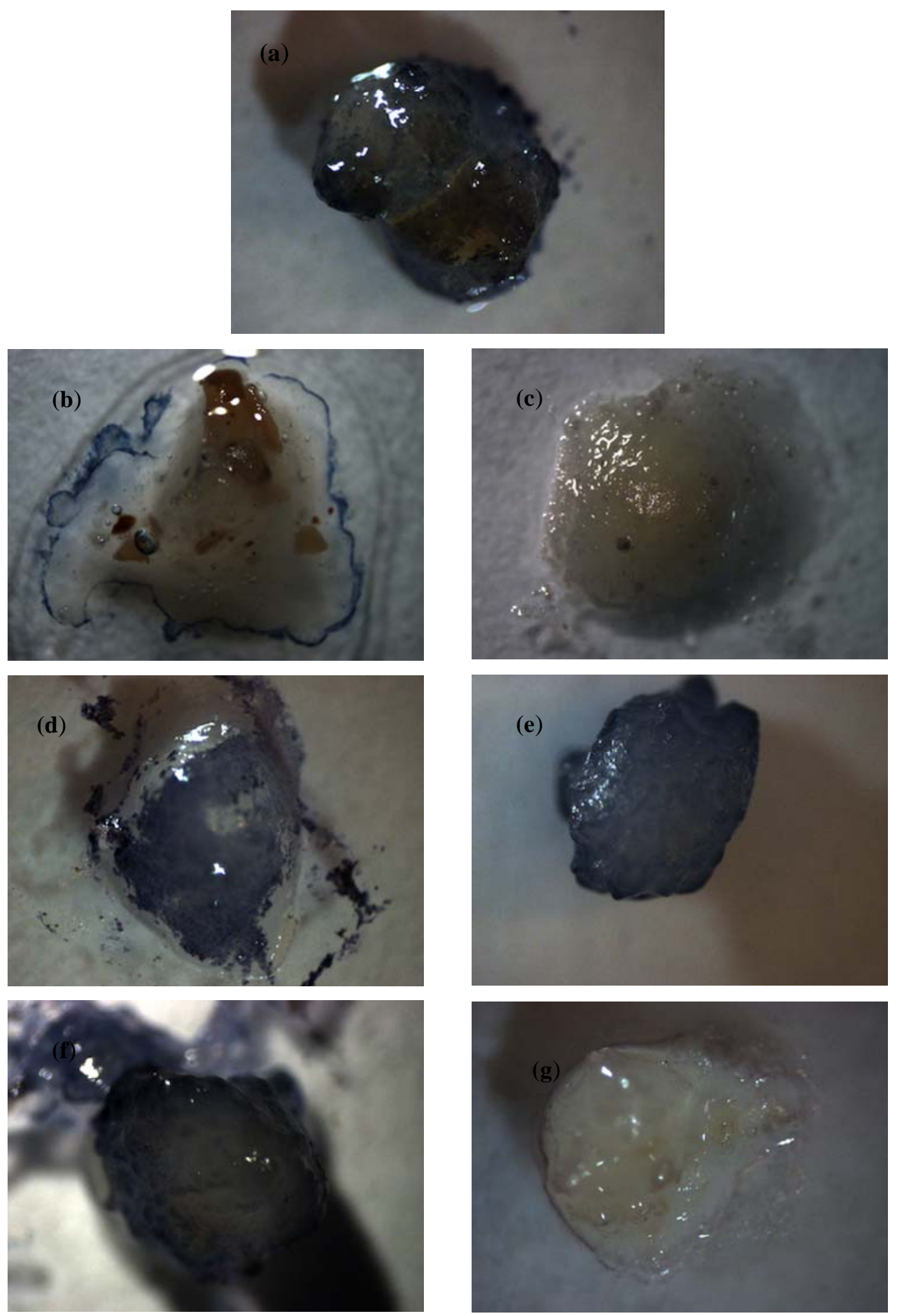

Figure 2. Lugol staining of single flour porridges (5× magnification) made from: (a) orange fleshed sweet potato (OFSP); (b) cowpea (CP); (c) dehulled soybean (DS); (d) dehulled sorghum (DSo); (e) dehulled maize (DM); (f) commercial maize (CM), and g) germinated maize (GM).

mately the same decrease in viscosity as $0.002 \mathrm{~g}$ of GM with time. Thereby, was concluded that the enzymatic activity of the CP flour could not explain the anomaly.

Looking for alternative explanation, measurements were performed of the swelling volume of the three indi- vidual flours (CP, OFSP and DS) and the blends CP-OFSP and CP-DS. The results are given in Table 2. It can clearly be seen that the volume fraction of the mixtures was lower than the sum of the volume fractions of the individual components according to Equation (1). It 


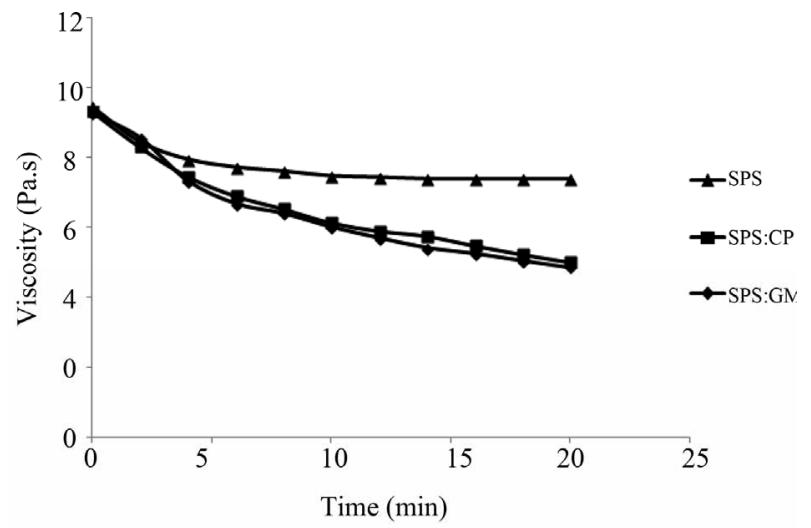

Figure 3. Comparison of amylolytic activity of $0.002 \mathrm{~g}$ of germinated maize (GM); and $0.2 \mathrm{~g}$ of cowpea (CP), measured as change of viscosity of a suspension of gelatinised potato starch (SPS). is known from particle packing theory that the individual distribution widths and the ratio of the components strongly affect the packing density in mixtures of different particles, as a fraction of the smaller particles can be accommodated in the voids between the larger particles [15]. The size distributions of diluted porridges made from OFSP, CP, or DS flour are shown in Figure 4, and the corresponding light microscope images in Figure 5. The size distributions of the separate flours are very different, and thus there is the possibility that the particle size distribution in the two-component porridge is responsible for the lower viscosity.

\section{Conclusions}

The results of the study show that the additive model is conservative, i.e. the consistency of the blends can be as

Table 1. Two-flour blends giving $C_{i} / C_{i \text {, adeq. }}=0.5$ when mixed with $40 \mathrm{ml}$ water.

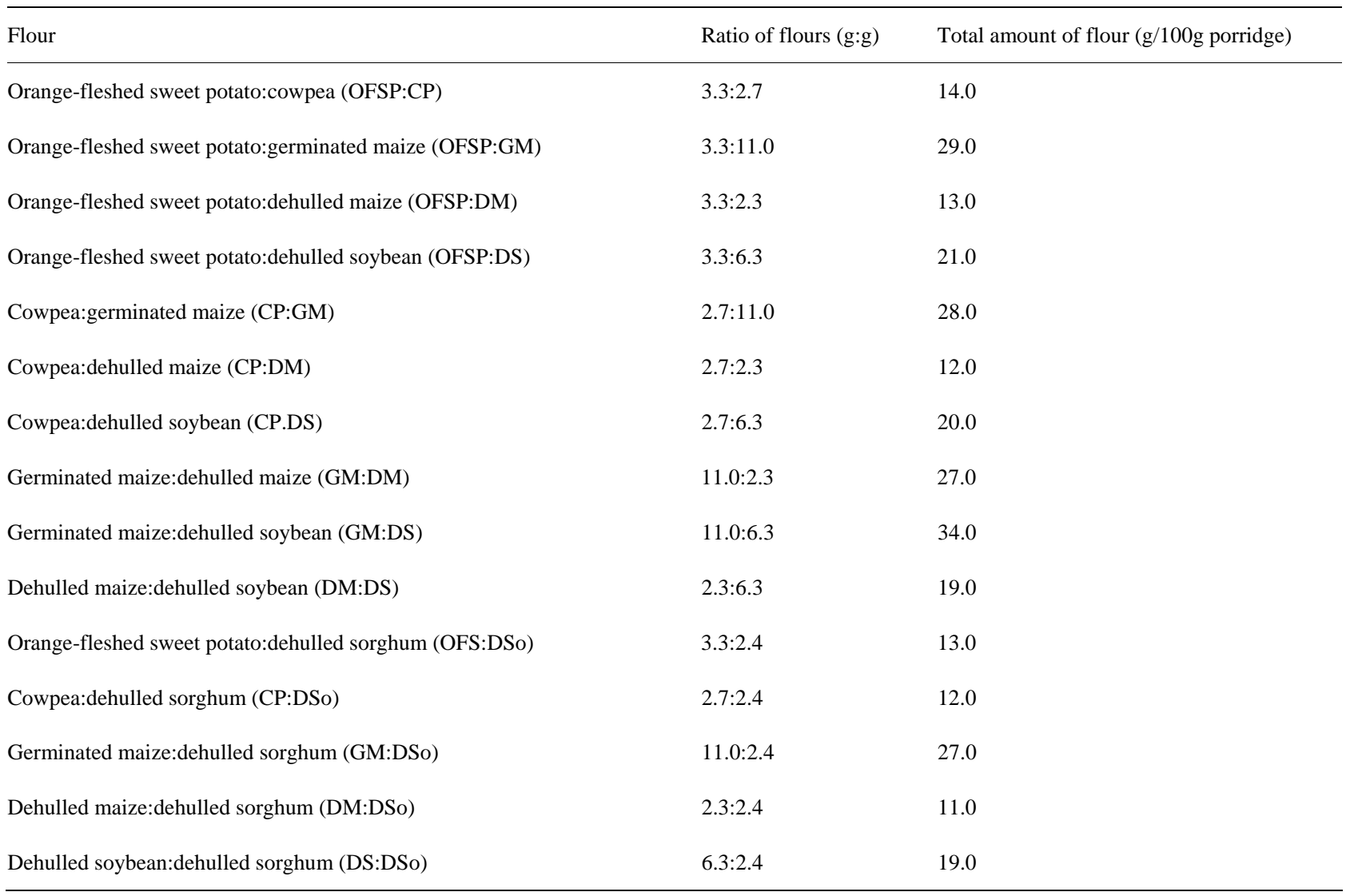

Table 2. Swelling of the three individual flours (CP, OFSP and DS) and the two-flour blends CP-OFSP and CP-DS (giving $C_{i} / C_{i \text {,adeq. }}=0.5$ ).

\begin{tabular}{lllll}
\hline Parameter & Flour & & Two-flour blends (Expected) \\
\hline Swelling (ml/g) & Cowpea (CP) $\begin{array}{l}\text { Orange-fleshed sweet } \\
\text { potato (OFSP) }\end{array}$ & $\begin{array}{l}\text { Dehulled } \\
\text { soybean (DS) }\end{array}$ & $\begin{array}{l}\text { Cowpea:Orange-fleshed } \\
\text { sweet potato (CP:OFSP) }\end{array}$ \\
\hline
\end{tabular}




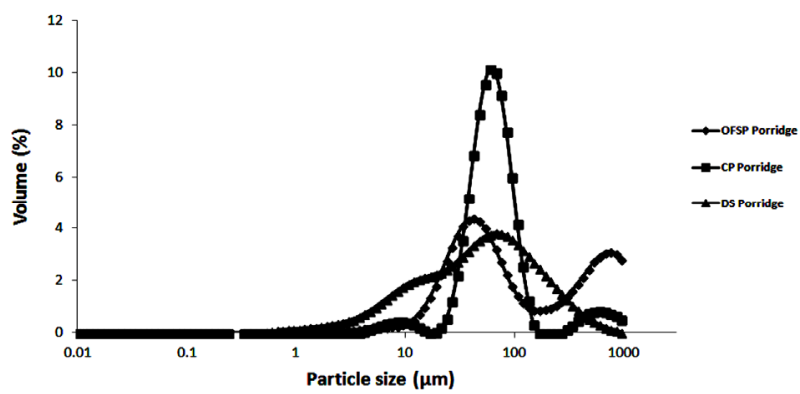

Figure 4. Mastersizer particle size distribution of single flour porridges made from: orange-fleshed sweet potato (OFSP); cowpea (CP); and dehulled soybean (DS).
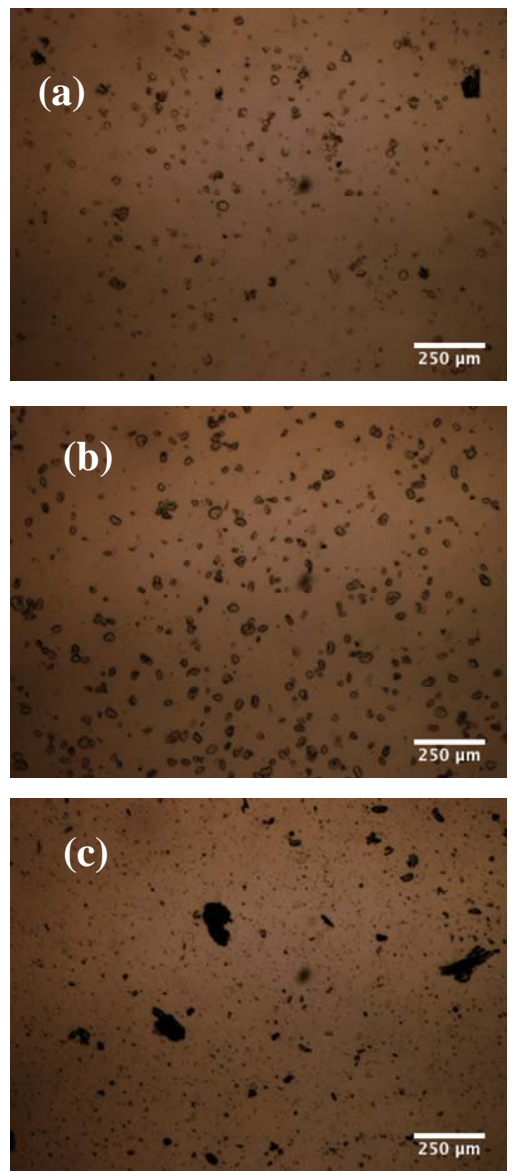

Figure 5. Light microscope images (2× magnification) of single flour porridges made from: (a) Orange-fleshed sweet potato (OFSP); (b) Cowpea (CP); and (c) Dehulled soybean (DS).

predicted from the consistency of the individual flours or lower. The underestimation of consistency for some of the blends containing CP flour is not a serious disadvantage. However, for blends containing GM flour, a quantitative model, allowing the prediction of the effect of the amylolytic and proteolytic activities on blend consistency, is necessary to make proper use of the beneficial effects of the enzymes.
This study laid the foundation for our future work using mathematical optimization to design nutritious supplementary foods for small children from blends of easily available local foodstuffs, while maintaining both a high energy density and an acceptable consistency.

\section{Acknowledgements}

This study was supported by the Swedish International Development Cooperation Agency (SIDA).

\section{REFERENCES}

[1] M. A. Rao, P. E., Okechukwu, P. M. S. Da Silva and J. C. Oliveira, "Rheological Behavior of Heated Starch Dispersions in Excess Water: Role of Starch Granule," Carbohydrate Polymers, Vol. 33, No. 4, 1997, pp. 273-283. doi:10.1016/S0144-8617(97)00025-8

[2] I. S. T. De Carvalho, Y. Granfeldt, A. C. Eliasson and P. Dejmek, "Predictability of the Consistency of Porridges Using Different Methods to Measure Flour Swelling," Starch/Stärk Journal, 2013, in press.

[3] U. Kidmose, L. O. Christensen, M. S. Agili and S. H. Thilsted, "Effect of Home Preparation Practices on the Content of Provitamin A Carotenoids in Coloured Sweet Potato Varieties (Ipomoea batatas Lam.) from Kenya," Innovative Food Science and Emerging Technologies, Vol. 8, No. 3, 2007, pp. 399-406. doi:10.1016/j.ifset.2007.03.025

[4] A. Bengtsson, A. Namutebi, M. Larsson and U. Svanberg, "Effects of Various Traditional Processing Methods on the All-Trans- $\beta$-Carotene content of Orange-Fleshed Sweet Potato," Journal of Food Composition and Analysis, Vol. 21, No. 2, 2008, pp. 134-143. doi:10.1016/j.jfca.2007.09.006

[5] S. Dakwa, E. Sakyi-Dawson, C. Diako, N. T. Annan and W. K. Amoa-Awua, "Effect of Boiling and Roasting on the Fermentation of Soybeans into Dawadawa (Soy-Dawadawa)," International Journal of Food Microbiology, Vol. 104, No. 1, 2005, pp. 69-82. doi:10.1016/j.ijfoodmicro.2005.02.006

[6] M. K. Bolade and M. S. Buraimoh, "Textural and Sensory Quality Enhancement of Sorghum tuwo,” International Journal of Food Science and Technology, Vol. 41, No. S2, 2006, pp. 115-123. doi:10.1111/j.1365-2621.2006.01437.x

[7] V. B. Tolstoguzov, "Functional Properties of ProteinPolysaccharide in Functional Properties of Food Macromolecules,” Aspen Publishers, Inc., New York, 1998, pp. 252-253.

[8] H. S. R. Deisikachar, "Development of Weaning Foods with High Caloric Density and Low Hot Paste Viscosity Using Traditional Technologies," Food and Nutrition Bulletin, Vol. 2, No. 4, 1980, pp. 21-23.

[9] A. C. Mosha and U. Svanberg, "Preparation of Weaning Foods with High Nutrient Density Using Flour of Germinated Cereals," Food and Nutrition Bulletin, Vol. 5, No. 2, 1983, pp. 10-14. 
[10] U. Svanberg, "Dietary Bulk in Weaning Foods and Its Effect on Food and Energy Intake,” In: D. Alnwick, S. Mose and O. G. Schimdt, Eds., Improving Young Child Feeding in Eastern and Southern Africa, Household-Level, Food Technology, IDRC, Ottawa, 1988, pp. 272-287.

[11] K. M. Maung, K. N. Maung and H. Lape, "Amylase Activity of Some Roots and Sprouted Cereals and Beans," Food Nutrition Bulletin, Vol. 16, No. 2, 1995, pp. 178181.

[12] J. K. Kikafunda, L. Abenakyo and F. B. Lukwago, "Nutritional and Sensory Properties of High Energy/Nutrient Dense Composite Flour Porridges from Germinated Maize and Roasted Beans for Child-Weaning in Developing Countries: A Case for Uganda," Ecology of Food and Nutrition, Vol. 45, No. 4, 2006, pp. 279-294.

$$
\text { doi:10.1080/03670240600846344 }
$$

[13] W. Mitsuhashi and A. Oaks, "Development of Endopeptidase Activities in Maize (Zea mays L.) Endosperms," Plant Physiology, Vol. 104, No. 2, 1994, pp. 401-407.

[14] V. A. Obatolu and A. H. Cole, "Functional Property of Complementary Blends of Soybean and Cowpea with Malted or Unmalted Maize,” Food Chemistry, Vol. 70, No. 2, 2000, pp. 147-153. doi:10.1016/S0308-8146(99)00248-4

[15] G. P. Bierwagen and T. E. Sanders, "Studies of the Effects of Particle Size Distribution on the Packing Efficiency of Particles,” Powder Technology, Vol. 10, No. 1, 1974, pp. 111-119. doi:10.1016/0032-5910(74)80036-7 